\title{
Effect of smoking on the proliferation capacity and osteogenic potential of human dental pulp stem cells (DPSCs)
}

\section{Wpływ nikotynizmu na zdolności proliferacyjne oraz potencjał kościotwórczy ludzkich komórek macierzystych miazgi zębowej}

\author{
Amany Hany Mohamed Kamel ${ }^{A-F}$, Samia Moustafa Kamal ${ }^{A, E, F}$, Nermeen AbuBakr ${ }^{A, E, F}$ \\ Department of Oral Biology, Faculty of Dentistry, Cairo University, Egypt \\ A - research concept and design; $B$ - collection and/or assembly of data; $C$ - data analysis and interpretation; \\ $D$ - writing the article; $E$ - critical revision of the article; $F$ - final approval of the article
}

Address for correspondence

Amany Hany Mohamed Kamel

E-mail: amany.hany@dentistry.cu.edu.eg

\section{Funding sources}

None declared

Conflict of interest

None declared

Received on September 9, 2019

Reviewed on 0ctober 8, 2019

Accepted on 0ctober 18, 2019

Published online on January 13,2020

Cite as

Kamel AHM, Kamal SM, AbuBakr N. Effect of smoking on the proliferation capacity and osteogenic potential of human dental pulp stem cells (DPSCS). Dent Med Probl. 2020;57(1):19-24. doi:10.17219/dmp/113179

DOI

$10.17219 / \mathrm{dmp} / 113179$

Copyright

○) 2020 by Wroclaw Medical University

This is an article distributed under the terms of the

Creative Commons Attribution 3.0 Unported License (CC BY 3.0)

(https://creativecommons.org/licenses/by/3.0/)

\begin{abstract}
Background. Recently, mesenchymal stem cells (MSCS) have proven to have a high potentiality in tissue regeneration. However, genetic diseases or certain environmental risk factors, such as smoking, may compromise the functioning of MSCs, thus leading to a change in the expected clinical outcomes.

Objectives. The aim of this study was to investigate the proliferation capacity and osteogenic potential of dental pulp stem cells (DPSCs) in smokers in comparison with non-smokers.

Material and methods. Mesenchymal stem cells were isolated from the cultured dental pulp tissue from the third molars of 5 smokers and 5 non-smokers. The proliferation capacity of DPSCs derived from both groups was measured using the 3-(4,5-dimethylthiazol-2-yl)-2,5-diphenyltetrazolium bromide (MTT) proliferation assay. Alizarin red staining and the gene expression analysis of the alkaline phosphatase (ALP) and osteocalcin (OC) genes were performed in order to assess osteogenic differentiation.

Results. The MTT proliferation assay revealed that the mean absorbance rate of the DPSCs of the nonsmokers was significantly higher than that of the group of smokers $(p<0.0001)$. When stained with alizarin red after 21 days of osteogenic induction, fewer calcium deposits were observed among the smokers. Moreover, the ALP and OC gene expression was significantly higher in the differentiated DPSCs of the nonsmokers $(p<0.05)$.

Conclusions. The group of smokers showed a reduced cell viability. The expression of the ALP and OC genes was lower in the DPSCS of the smokers. Therefore, smoking has a negative impact on the proliferation and regenerative potential of human MSCS.
\end{abstract}

Key words: smoking, dental pulp, mesenchymal stem cells, osteogenic

Słowa kluczowe: nikotynizm, miazga zębowa, mezenchymalne komórki macierzyste, kościotwórczy 


\section{Introduction}

Mesenchymal stem cells (MSCs) have gained worldwide attention in the past few decades due to their great potential in tissue regeneration and repair. ${ }^{1}$ Mesenchymal stem cells are capable of synthesizing various cytokines and growth factors that boost local cellular dynamics. Besides their immunomodulatory effect, MSCs release proangiogenic and chemotactic factors, thus playing a major role in wound healing, bone remodeling and overall tissue regeneration..$^{2,3}$ However, recent studies have shown that exposure to cigarette smoke significantly inhibits the regenerative capacity of MSCs. Smoke components may reduce the number and quality of stem cells deposited in tissue reservoirs. ${ }^{4-9}$

The unfavorable effect of the components of tobacco smoke on MSCs includes both the direct impact on the cells and their organizational mechanisms, and alterations in the environment of MSCs. Both mechanisms contribute to limiting the regenerative potential of these cells. ${ }^{10}$ In addition, the content of nicotine - as one of the main ingredients of cigarette smoke - has been determined to be nearly 87 times higher in the saliva than in the blood plasma. ${ }^{11}$ Being subjected to high doses of nicotine may result in harm to the MSC populations in the oral cavity. One such group is dental pulp stem cells (DPSCs), which have similar characteristics to bone marrow mesenchymal stem cells (BMMSCs). ${ }^{12}$ It has been established that DPSCs are characterized by being highly proliferative and by their multipotent differentiation capacity. Dental pulp stem cells can differentiate in vitro into odontoblasts, osteoblasts and chondrocytes to produce dentin, bone and cartilage tissues, respectively, for the repair process. ${ }^{13-17}$

Although cigarette smoking inhibits stem cell recruitment to tissues, thus affecting regeneration, ${ }^{18,19}$ studies investigating its effect on stem cell proliferation and potentiality are limited. The present study aimed at investigating the deleterious effect of smoking on the proliferation capacity and osteogenic potential of human DPSCs in vitro.

\section{Material and methods}

\section{Ethical statement}

The study was conducted at the Department of Biochemistry and Molecular Biology, Faculty of Medicine of Cairo University in Egypt. All of the experimental protocols were performed in accordance with the guidelines of the Ethics Committee of the Faculty of Dentistry of Cairo University (approval No. 9/3/16). All eligible patients signed their informed, written consent.

\section{Tooth collection and the culturing of dental pulp stem cells}

The MSCs used in this study were derived from the dental pulp (DPSCs) of normal, sound, impacted third molars taken from 5 cigarette smokers and 5 adult, non-smoking donors, aged 25-35 years. The definition of a smoker was determined according to the National Health Interview Survey (NHIS) standard: an adult who has smoked at least 100 cigarettes. ${ }^{20}$ All donors were healthy, free from systemic diseases, nondrinkers, and were not on any medications. They were recruited from the outpatient dental clinic at the Faculty of Dentistry of Cairo University. Informed consent was obtained from each donor before the teeth were extracted. Following extraction, each tooth was cut at the cementoenamel junction to reveal the pulp chamber and to obtain the dental pulp tissue.

Dental pulp stem cells from both groups were isolated by the enzymatic dissociation method. The excised tissues were minced under sterile conditions into small pieces, to which a digesting solution of $3 \mathrm{mg} / \mathrm{mL}$ of collagenase type II was added (Worthington Biochemical Corp., Lakewood, USA) for $2 \mathrm{~h}$ at $37^{\circ} \mathrm{C}$. Single-cell suspensions were obtained by passing the cell suspension through a 70-micrometer strainer (BD Biosciences, San Jose, USA). The suspension was incubated in the Roswell Park Memorial Institute (RPMI) medium (Thermo Fisher Scientific, Waltham, USA), which was supplemented with $10 \%$ fetal bovine serum (FBS) (Thermo Fisher Scientific), antibiotics (100 units/mL of penicillin $\mathrm{G}$ and $100 \mu \mathrm{g} / \mathrm{mL}$ of streptomycin) and an antimycotic agent (Fungizone ${ }^{\circledR}-0.25 \mu \mathrm{g} / \mathrm{mL}$ ) (Thermo Fisher Scientific) in a humid atmosphere with $5 \% \mathrm{CO}_{2}$. The culture medium was changed every 3 days until confluence was achieved. The cells were successfully passaged up to the $3^{\text {rd }}$ passage (P3); these were the cells used in the subsequent experiments. The culture medium was replaced every 3 days over a 21-day period.

\section{Flow cytometric analysis}

The isolated stem cells were characterized by analyzing the cell surface antigen expression. Adherent cells from dental pulp at $\mathrm{P} 3$ were detached using $0.05 \%$ trypsin and adjusted to $1 \times 10^{5}$ cells $/ \mathrm{mL}$. Then, $1 \times 10^{5}$ cells were incubated with $10 \mu \mathrm{L}$ of the monoclonal antibodies against CD29, CD34, CD45, CD90, and CD105 (Beckman Coulter, Inc., Miami, USA) for $30 \mathrm{~min}$ at $4{ }^{\circ} \mathrm{C}$ in the dark. Isotopes served as a negative control. The cell analysis was performed using the Cytomics $^{\mathrm{TM}}$ FC 500 flow cytometer (Beckman Coulter, Inc.) and the data was analyzed using the CXP software, v. 2.2 (Beckman Coulter, Inc.). 


\section{MTT cell proliferation assay}

Cells at P3 were seeded in polylysine-coated 96-well plates at $1 \times 10^{3}$ cells/well (SPL Life Sciences Co., Ltd., Pyeongtaek, South Korea). The cells were incubated with the 3-(4,5-dimethylthiazol-2-yl)-2,5-diphenyltetrazolium bromide (MTT) reagent (Thermo Fisher Scientific), $50 \mathrm{mg} / \mathrm{vial}$. The proliferation was then assessed using the absorbance quantitative enzymelinked immunosorbent assay (ELISA) at a wavelength of $450 \mathrm{~nm}$.

\section{Osteogenic differentiation}

Cells from both groups at P3 were plated into each well of a flat-bottom 24-well plate (SPL Life Sciences Co., Ltd.) at a density of $2 \times 10^{3} / \mathrm{cm}^{2}$ with an osteogenic induction medium - human StemXVivo ${ }^{\circledR}$ Osteogenic/Adipogenic Base Media (catalog No. CCM007) and human StemXVivo ${ }^{\circledR}$ Osteogenic Supplement (catalog No. CCM008) (R\&D Systems, Minneapolis, USA) for 21 days. The medium was changed twice a week. The cells were observed regularly for morphological changes using an inverted-light microscope (Olympus America, Inc., Center Valley, USA), with a digital camera (Nikon, Tokyo, Japan) for capturing images. Dental pulp stem cells cultured in the basic medium were used as controls.

\section{Alizarin red staining}

After 21 days of osteogenic induction, the differentiated DPSCs from both groups were rinsed twice with phosphate-buffered saline (PBS) and fixed in $10 \%$ buffered formalin for $10 \mathrm{~min}$ at room temperature. The fixative was carefully removed and the cells were gently rinsed 3 times with distilled water, and then stained with $1 \%$ alizarin red solution (birefringent end product) (Sigma-Aldrich Co., St. Louis, USA) for $20 \mathrm{~min}$ at room temperature. The alizarin red solution was removed and the plates were washed 4 times with $1 \mathrm{~mL}$ of distilled water. The stained mineralized nodules were monitored using an inverted-light microscope and digital micrographs were taken.

\section{Real-time quantitative polymerase chain reaction}

On day 21 of osteogenic induction, total RNA was isolated from all of the cultured DPSCs of the smoker and non-smoker groups using a cell extraction kit (Qiagen Sciences, Inc., Germantown, USA), and was analyzed for quantity and quality with a Beckman dual spectrophotometer (Beckman Coulter, Inc.). The synthesis of cDNA was performed using $1 \mu \mathrm{g}$ of the total
RNA and a high-capacity cDNA reverse transcription kit (catalog No. K1621; Fermentas, Waltham, USA). The cDNA was subsequently amplified with the SYBR $^{\mathrm{TM}}$ Green I PCR Master Mix (Fermentas) using the StepOne ${ }^{\mathrm{TM}}$ instrument (Applied Biosystems, Foster City, USA). The primers used for real-time polymerase chain reaction (PCR) were as follows: glyceraldehyde 3-phosphate dehydrogenase (GAPDH), forward: 5'-AGGTCGGTGTGAACGGATTTG-3' and reverse: 5'-TGTAGACCATGTAGTTGAGGTCA-3'; alkaline phosphatase $(A L P)$, forward: 5'-ACGTGGCTAAGAATGTCATC-3' and reverse: 5'-CTGGTAGGCGATGTCCTTA-3'; osteocalcin (OC), forward: 5'-CAAAGGTGCAGCCTTTGTGTC-3' and reverse: 5'-TCACAGTCCGGATTGAGCTCA-3'. The expression levels in the DPSCs of the smoker group were compared to those in the DPSCs of the non-smokers and the controls after normalization to GAPDH.

\section{Statistical analysis}

The data was analyzed using IBM SPSS Statistics for Windows, v. 21 (IBM Corp., Armonk, USA). Numerical data is presented as means \pm standard deviation $(S D)$. The independent $t$-test was used to compare the means between the groups of smokers and non-smokers. If any significance was detected, Tukey's post hoc test was used to determine which group was responsible for the significance. Significance was defined as a $p$-value of $<0.05$.

\section{Results}

\section{Morphological assessment, flow cytometric analysis and proliferation activity assessment}

Pulpal stem cells were successfully isolated from both groups, adhered to plastic and proliferated, reaching $70 \%$ confluence by day 14 . By day 21, all cells acquired a uniform, spindle-shaped morphology, whereby the cells in the non-smoker group appeared to be more numerous (Fig. 1).

The flow cytometric analysis showed that the DPSCs expressed stem cell surface markers CD29, CD90 and CD105 in over 90\%. Contrarily, the hematopoietic cell markers CD34 and CD45 were expressed in a very small percentage $(<5 \%)$ (Fig. 2).

The MTT proliferation assay showed that the mean absorbance rate of the DPSCs of the non-smoker group $(4.242 \pm 0.748 ; \mathrm{n}=5)$ was significantly higher than in the case of the smoker group $(1.992 \pm 0.493 ; \mathrm{n}=5)$ at $p<0.0001$ (Fig. 3). 


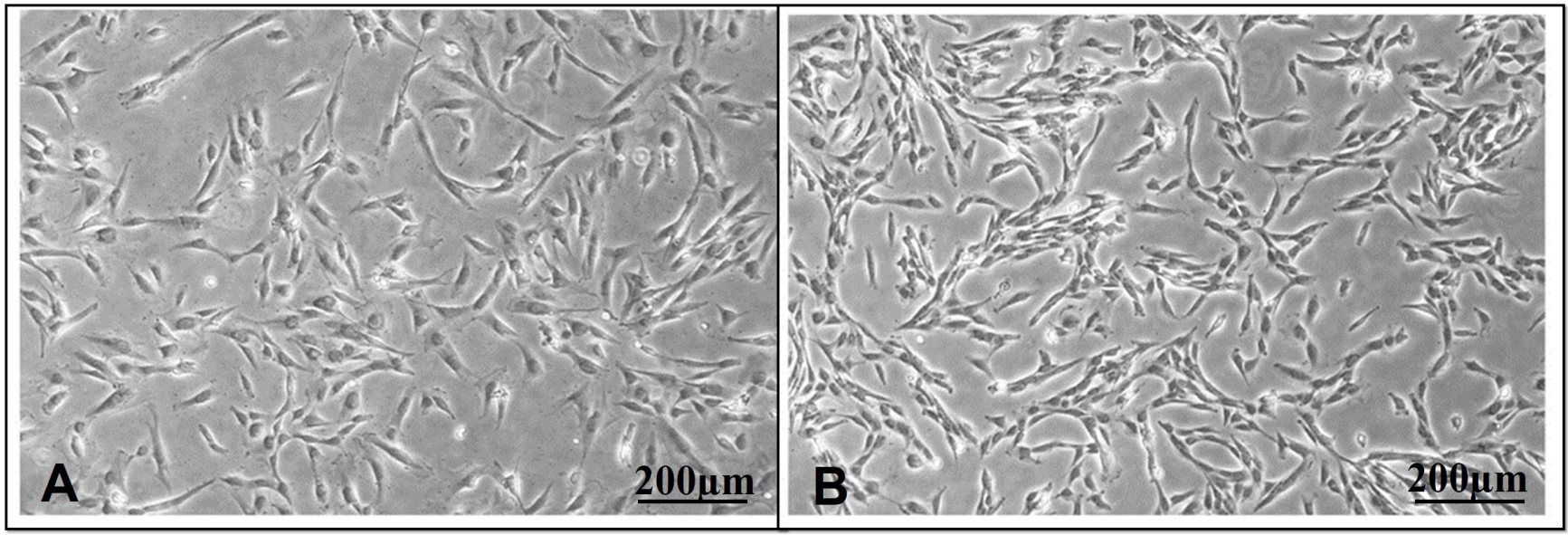

Fig. 1. Morphology of the dental pulp stem cells (DPSCs) from the smoker (A) and non-smoker groups (B) on day 21
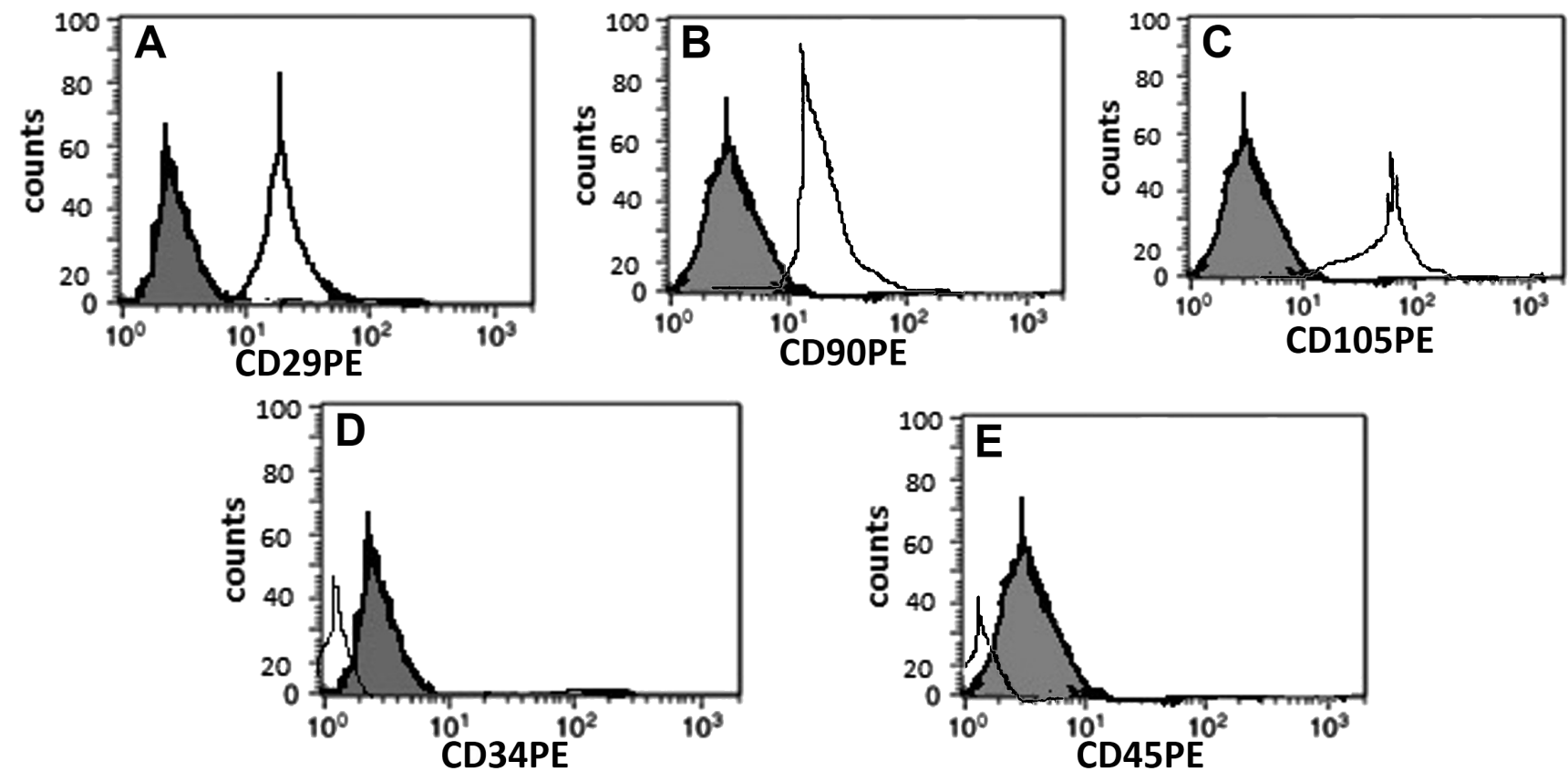

Fig. 2. Representative histograms of the flow cytometric analysis of DPSCs, showing the expression of surface markers: CD29 (A), CD90 (B), CD105 (C), CD34 (D), and CD45 (E)

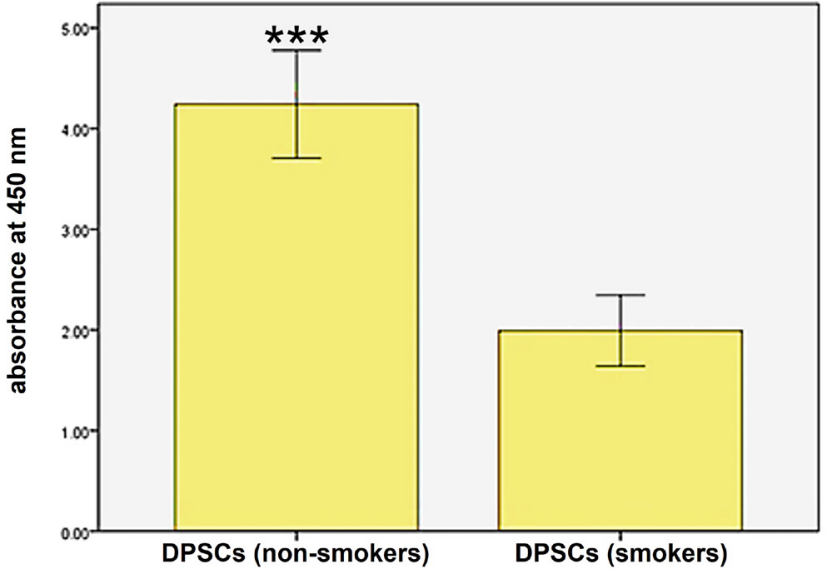

Fig. 3. MTT proliferation assay

MTT - 3-(4,5-dimethylthiazol-2-yl)-2,5-diphenyltetrazolium bromide. A significant decrease in proliferation was detected in the DPSCs of smokers as compared to non-smokers. Data expressed as mean \pm standard deviation (SD); ${ }^{* *} p<0.0001$.

\section{Osteogenic differentiation assessment}

When stained with alizarin red after 21 days of osteogenic induction, a reduced calcium deposition was observed in the DPSCs of the smokers, whereas none was detected in the control cultures (Fig. 4).

When the expression of the $A L P$ and $O C$ genes was compared, it turned out that the expression of both genes was significantly higher in the differentiated DPSCs of the non-smoker group (ALP: $0.854 \pm 0.439$; $O C: 1.938 \pm 0.818 ; \mathrm{n}=5)$ than in those of the smoker group (ALP: $0.480 \pm 0.211 ; O C: 1.017 \pm 0.597 ; \mathrm{n}=5)$ at $p<0.05$, whereas the cells in the control cultures did not express the genes at all (Fig. 5,6). 


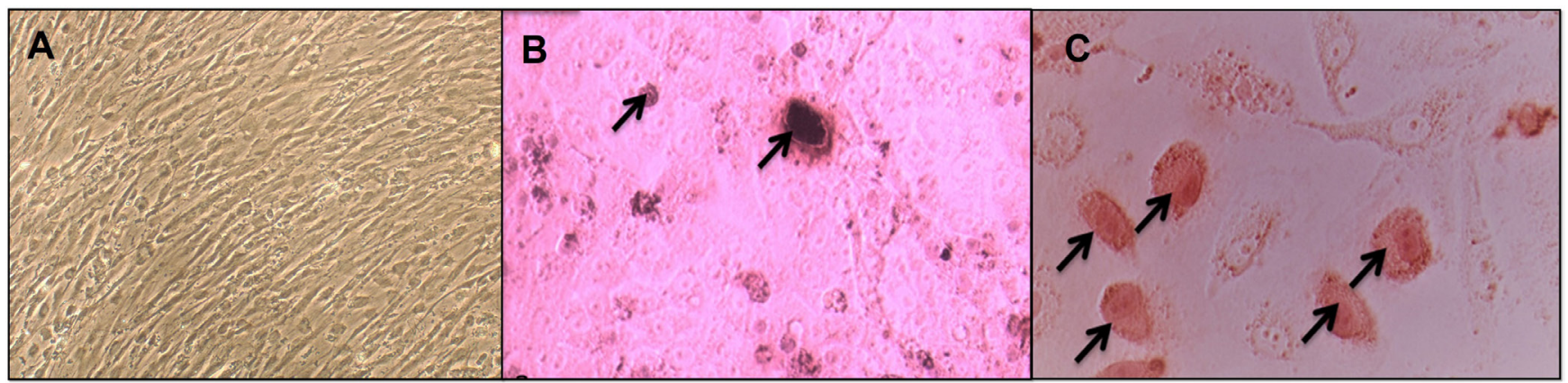

Fig. 4. Alizarin red staining showing calcified areas on day 21 of osteogenic induction, which were more numerous in the non-smoker group as compared to other groups

A - controls; B - DPSCs (smokers); C - DPSCs (non-smokers).

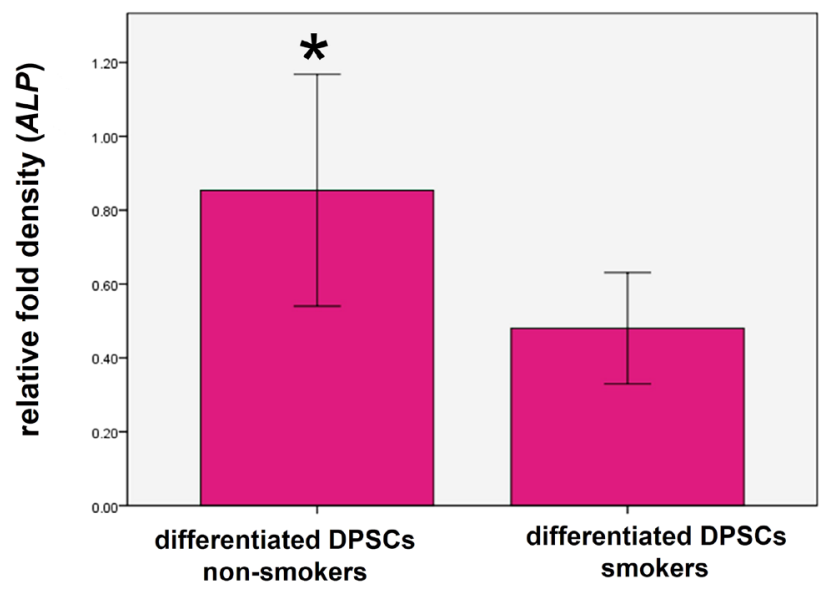

Fig. 5. Quantitative real-time polymerase chain reaction (RT-PCR) for the mRNA levels of the ALP gene, showing a significantly higher expression of the gene in the DPSCs of the non-smokers

Data expressed as mean $\pm S D ;{ }^{*} p<0.05$.

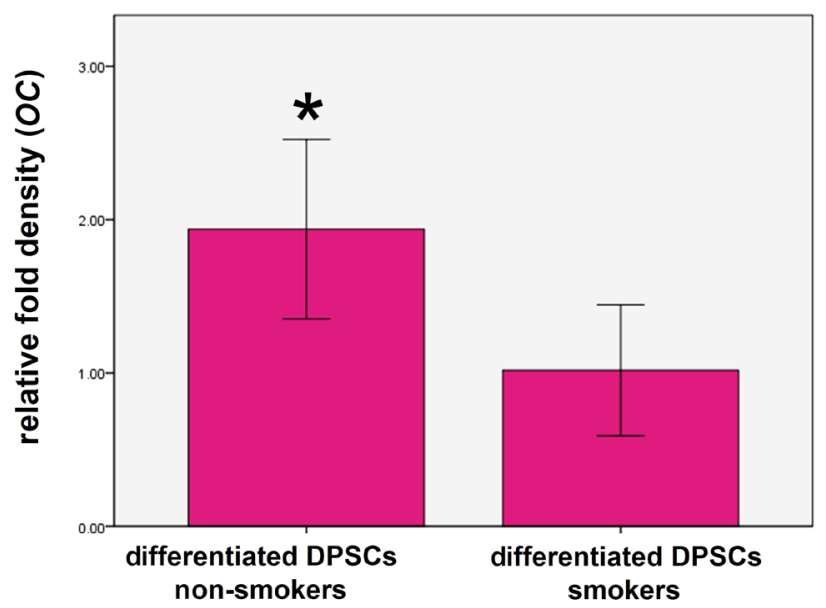

Fig. 6. Quantitative RT-PCR for the mRNA levels of the OC gene, showing a significantly higher expression of the gene in the DPSCs of the non-smokers Data expressed as mean $\pm S D ;{ }^{*} p<0.05$.

\section{Discussion}

Mesenchymal stem cells are frequently considered for various applications in regenerative medicine, being capable of self-renewal in addition to their potentiality to form different cell types..$^{12}$ Stem cells are routinely screened prior to transplantation in order to exclude any infectious disease or genetic disturbance that might interfere with the functioning of MSCs. However, the existence of environmental predisposing conditions, such as cigarette smoking, can be missed, and this may affect the ability of MSCs to differentiate and may make the cells unsuitable for transplantation. ${ }^{11}$

Consequently, we investigated the proliferation capacity and osteogenic potential of DPSCs in smokers vs non-smokers. In the present study, MSCs were isolated and expanded from the dental pulp tissue of 10 patients comprising the smoker group $(\mathrm{n}=5)$ and the non-smoker group $(\mathrm{n}=5)$.

In addition to the excellent proliferation ability and mineralization potential of DPSCs, they can be obtained easily. Thus, numerous scientists have studied the isolation and osteogenic potential of DPSCs, but nobody has studied the impact of smoking on their function..$^{21,22}$

In this study, the cell proliferation analysis showed that the mean absorbance rate of the DPSCs in the non-smoker group was significantly higher than that in the smoker group $(p<0.0001)$. This finding is in agreement with $\mathrm{Ng}$ et al., who found that the proliferation rates of periodontal ligament stem cells (PDLSCs) isolated from smokers showed a 2.53-fold decrease compared with the cells derived from non-smokers. ${ }^{9}$ A decreased proliferation was still observed even after sub-culturing the cells 3-5 times, suggesting that exposure to nicotine may have a prolonged or even permanent effect on the cells. ${ }^{9}$

It is well-known that cigarette smoking delays healing, which can be attributed to disturbance in the regenerative ability of MSCs. Previous reports have studied the effect of nicotine exposure on non-smokers' dental stem cells. ${ }^{7,823}$ However, few studies have investigated the regenerative potential of stem cells in direct relation to cigarette smoking. ${ }^{9}$

In this study, we examined 2 major important processes that regulate the regenerative potential of stem cells: cell proliferation and differentiation. ${ }^{24}$

The cigarette smoke extract was found to inhibit osteoprogenitor cell proliferation..$^{5}$ In addition, nicotine also hinders the proliferation of PDLSCs. ${ }^{8}$ Our results 
further proved that the proliferation rate and/or cell viability of DPSCs from smokers is lower than in the case of non-smokers.

Regarding cell differentiation, several studies have highlighted the capacity of DPSCs to differentiate into functional osteoblasts in vitro, ${ }^{25,26}$ but no one has examined the damaging effect of smoking. In the present study, we assessed the expression of both $A L P$ as an early bone marker and $O C$ as a late bone marker. In addition, we used alizarin red staining after 21 days of osteogenic induction to detect any calcified deposits.

The expression of both the $A L P$ and $O C$ genes was significantly higher in the differentiated DPSCs of the nonsmoker group than in the smoker group $(p<0.05)$. Alizarin red staining showed a reduced calcium deposition in the smokers' DPSCs. Our results are in agreement with those of $\mathrm{Ng}$ et al., who found that the PDLSCs of smokers exhibited an overall reduction in calcium deposition and in the production of ALP compared with non-smokers after 14 days of osteogenic differentiation in vitro. ${ }^{9}$ Moreover, Zhou et al. reported that nicotine affected the osteogenic differentiation of MSCs in vitro, and found that exposure to $1 \mathrm{mM}$ of nicotine significantly decreased the inherent RUNX2, COL1A1, COL1A2, ALP, and OC gene expression in both human BMMSCs (hBMMSCs) and human PDLSCs (hPDLSCs) $(p<0.05)$ after just 3 days of exposure. $^{7}$

\section{Conclusions}

This study showed that the proliferation and osteogenic differentiation abilities of human DPSCs from smokers were altered. Thus, smoking could have a negative impact on the proliferation and regenerative potential of human MSCs.

\section{ORCID iDs}

Amany Hany Mohamed Kamel (1) https://orcid.org/0000-0002-3562-1099 Samia Moustafa Kamal (1) https://orcid.org/0000-0002-0674-0646 Nermeen AbuBakr (1) https://orcid.org/0000-0003-2962-0070

\section{References}

1. Biehl JK, Russell B. Introduction to stem cell therapy. J CardiovasC Nurs. 2009;24(2):98-105.

2. Caplan Al, Dennis JE. Mesenchymal stem cells as trophic mediators. J Cell Biochem. 2006;98(5):1076-1084.

3. Maumus M, Guérit D, Toupet K, Jorgensen C, Noël D. Mesenchymal stem cell-based therapies in regenerative medicine: Applications in rheumatology. Stem Cell Res Ther. 2011;2(2):14.

4. Lee JJ, Patel R, Biermann JS, Dougherty PJ. The musculoskeletal effects of cigarette smoking. J Bone Joint Surg Am. 2013;95(9):850-859.

5. Kim BS, Kim SJ, Kim HJ, et al. Effects of nicotine on proliferation and osteoblast differentiation in human alveolar bone marrow-derived mesenchymal stem cells. Life Sci. 2012;90(3-4):109-115.

6. Shen Y, Liu HX, Ying XZ, et al. Dose-dependent effects of nicotine on proliferation and differentiation of human bone marrow stromal cells and the antagonistic action of vitamin C. J Cell Biochem. 2013;114(8):1720-1728.
7. Zhou Z, Li B, Dong Z, et al. Nicotine deteriorates the osteogenic differentiation of periodontal ligament stem cells through a7 nicotinic acetylcholine receptor regulating wnt pathway. PLoS One. 2013;8(12):e83102.

8. Ng TK, Carballosa CM, Pelaez D, et al. Nicotine alters MicroRNA expression and hinders human adult stem cell regenerative potential. Stem Cells Dev. 2013;22(5):781-790.

9. Ng TK, Huang L, Cao D, et al. Cigarette smoking hinders human periodontal ligament-derived stem cell proliferation, migration and differentiation potentials. Sci Rep. 2015;5:7828.

10. Jędrzejas M, Skowron K, Czekaj P. Stem cell niches exposed to tobacco smoke. Przegl Lek. 2012;69(10):1063-1073.

11. Greenberg JM, Carballosa CM, Cheung HS. Concise review: The deleterious effects of cigarette smoking and nicotine usage and mesenchymal stem cell function and implications for cell-based therapies. Stem Cells Transl Med. 2017;6(9):1815-1821.

12. Liu J, Yu F, Sun Y, et al. Concise reviews: Characteristics and potential applications of human dental tissue-derived mesenchymal stem cells. Stem Cells. 2015;33(3):627-638.

13. Wei $X$, Ling J, Wu L, Liu L, Xiao Y. Expression of mineralization markers in dental pulp cells. J Endod. 2007;33(6):703-708.

14. Zhang W, Walboomers XF, Shi S, Fan M, Jansen JA. Multilineage differentiation potential of stem cells derived from human dental pulp after cryopreservation. Tissue Eng. 2006;12(10):2813-2823.

15. Koyama N, Okubo Y, Nakao K, Bessho K. Evaluation of pluripotency in human dental pulp cells. J Oral Maxillofac Surg. 2009;67(3):501-506.

16. Cheng PH, Snyder B, Fillos D, Ibegbu CC, Huang AH, Chan AW. Postnatal stem/progenitor cells derived from the dental pulp of adult chimpanzee. BMC Cell Biol. 2008;9:20.

17. d'Aquino R, Graziano A, Sampaolesi M, et al. Human postnatal dental pulp cells co-differentiate into osteoblasts and endotheliocytes: A pivotal synergy leading to adult bone tissue formation. Cell Death Differ. 2007;14(6):1162-1171.

18. Zhou Y, Gan Y, Taylor HS. Cigarette smoke inhibits recruitment of bone-marrow-derived stem cells to the uterus. Reprod Toxicol. 2011;31(2):123-127.

19. Chen Y, Guo Q, Pan X, Qin L, Zhang P. Smoking and impaired bone healing: Will activation of cholinergic anti-inflammatory pathway be the bridge? Int Orthop. 2011;35(9):1267-1270.

20. Ryan H, Trosclair A, Gfroerer J. Adult current smoking: Differences in definitions and prevalence estimates - NHIS and NSDUH, 2008. J Environ Public Health. 2012;2012:918368.

21. Yasui T, Mabuchi Y, Morikawa S, et al. Isolation of dental pulp stem cells with high osteogenic potential. Inflamm Regen. 2017;37:8.

22. Kamel AHM, Kamal SM, Rashed LA, Ahmed NE. Proliferation capacity and osteogenic potential of human gingival stem cells versus human dental pulp stem cells. J Stem Cells. 2019;14(1):21-30.

23. Kim SY, Kang KL, Lee JC, Heo JS. Nicotinic acetylcholine receptor $\alpha 7$ and $\beta 4$ subunits contribute nicotine-induced apoptosis in periodontal ligament stem cells. Mol Cells. 2012;33(4):343-350.

24. Frescaline G, Bouderlique T, Huynh MB, Papy-Garcia D, Courty J, Albanese P. Glycosaminoglycans mimetics potentiate the clonogenicity, proliferation, migration and differentiation properties of rat mesenchymal stem cells. Stem Cell Res. 2012;8(2):180-192.

25. Teti G, Salvatore V, Focaroli S, et al. In vitro osteogenic and odontogenic differentiation of human dental pulp stem cells seeded on carboxymethyl cellulose-hydroxyapatite hybrid hydrogel. Front Physiol. 2015;6:297.

26. Tabatabaei FS, Torshabi M. In vitro proliferation and osteogenic differentiation of endometrial stem cells and dental pulp stem cells. Cell Tissue Bank. 2017;18(2):239-247. 